\title{
From Utopia to Science: Challenges of Personalised Genomics Information for Health Management and Health Enhancement
}

\author{
Hub Zwart
}

Received: 4 April 2009/Accepted: 7 July 2009/Published online: 24 July 2009

(C) The Author(s) 2009. This article is published with open access at Springerlink.com

\begin{abstract}
From 1900 onwards, scientists and novelists have explored the contours of a future society based on the use of "anthropotechnologies" (techniques applicable to human beings for the purpose of performance enhancement ranging from training and education to genome-based biotechnologies). Gradually but steadily, the technologies involved migrated from (science) fiction into scholarly publications, and from "utopia" (or "dystopia") into science. Building on seminal ideas borrowed from Nietzsche, Peter Sloterdijk has outlined the challenges inherent in this development. Since time immemorial, and at least
\end{abstract}

This article is part of the Research Programme of the Centre for Society \& Genomics, funded by the Netherlands Genomics Initiative.

H. Zwart $(\bowtie)$

Faculty of Science, Institute for Science, Innovation and Society, Radboud University Nijmegen, Huijgens Building Heyendaalseweg, Room: 02.808,

1356525 AJ Nijmegen, The Netherlands

e-mail: h.zwart@science.ru.nl

URL: www.filosofie.science.ru.nl

\section{H. Zwart}

Department of Philosophy and Science Studies, Radboud University Nijmegen, Huijgens Building Heyendaalseweg, 1356525 AJ Nijmegen,

The Netherlands

H. Zwart

Centre for Society and Genomics, P.O. Box 90106500

GL, Nijmegen, The Netherlands since the days of Plato's Academy, human beings have been interested in possibilities for (physical or mental) performance enhancement. We are constantly trying to improve ourselves, both collectively and individually, for better or for worse. At present, however, new genomics-based technologies are opening up new avenues for self-amelioration. Developments in research facilities using animal models may to a certain extent be seen as expeditions into our own future. Are we able to address the bioethical and biopolitical issues awaiting us? After analyzing and assessing Sloterdijk's views, attention will shift to a concrete domain of application, namely sport genomics. For various reasons, top athletes are likely to play the role of genomics pioneers by using personalized genomics information to adjust diet, life-style, training schedules and doping intake to the strengths and weaknesses of their personalized genome information. Thus, sport genomics may be regarded as a test bed where the contours of genomics-based self-management are tried out.

Keywords Genomics - Sport genomics · Personalised genomics - Anthropotechnologies . Science novels · Bioethics - Peter Sloterdijk

\section{Begin at the beginning}

"I shall begin at the beginning", said the DHC [Director of Hatcheries and Conditioning], and 
the more zealous students recorded his intentions in their notebooks: Begin at the beginning. "These", he waved his hand, "are the incubators." And in opening an insulated door he showed them racks upon racks of numbered test-tubes. "The week's supply of ova. Kept", he explained, "at blood heat; whereas the male gametes", and here he opened another door, "they have to be kept at thirty-five instead of thirty-seven". Still leaning against the incubators he gave them ... a brief description of the modern fertilizing process; spoke first, of course, of its surgical introduction - "the operation undergone voluntarily for the good of Society, not to mention the fact that it carries a bonus amounting to six months' salary..." etc. (Huxley 1932/1947, p. 9).

This quotation was taken from the famous opening chapter of Aldous Huxley's novel Brave New World (1947) in which literary tools are used for an exploration of the future. Huxley did not write his novel in a vacuum, ex nihilo, of course. On the contrary, it was a contribution to an already existing stream of literature that had begun to emerge around 1900 and consisted of publications written predominantly by authors who were scientist, novelists, or both. Gradually but steadily, the ideas addressed in these writings migrated from novels, plays and stories into scientific publications. Indeed, in the course of the 20th century, there was a steady trek of such ideas from utopia (or dystopia) to science, to borrow a famous title from the writings of Friedrich Engels (1880/1976). What Engels outlined with regard to socialism, applies to bioscience as well: due to the initial immaturity of scientific developments, the visions involved, envisioning an "ideal" sciencedriven society (as alluring as they were uncanny), were more a matter of foresight and fiction than reality. They were idealistic and even naïve, and condemned to producing utopian (or dystopian) views-utopian or dystopian depending on the (technophilic or technophobic) denomination of the reader. And the more these views were fleshed out in detail, the more their phantasmatic nature became apparent. Yet, in the course of the century, this clearly changed. In 1978 Louise Brown, the first IVF child was born, an important milestone for reproductive biomedicine, but also an example of science fiction becoming reality, or utopia becoming science. In public media, this "test-tube" baby was emphatically presented as a perfectly normal and healthy child. Yet a technique that was initially directed towards reproducing normalcy, could in principle provide a window for modification and enhancement as well.

Finally, the century that began with Mendel and Loeb resulted in a famous Press Conference (June 26 2000) where President Bill Clinton, together with Francis Collins and Craig Venter, formally announced that the human genome sequencing effort was nearing its completion, opening-up a plethora of potential uses of human genomics information in various fields. The press conference amounted to something of a science show, the penultimate movement in a technoscientific strip-tease, for in reality nature still strived to conceal herself even then, as Herakleitos had already stated: the Consortium had to continue its sequencing efforts for another 4 years to come before the Human Genome Project could really be considered "completed".

The question I intend to address in this article is how we are to assess the bioethical and biopolitical challenges these developments entail for health management by individuals and society, for personal as well as for public health. There is a widespread conviction that, as scientific research is moving into new terrain, philosophical and bioethical discourses are challenged to adapt themselves to the novel circumstances thus emerging. Massive, technologydriven research efforts, directed at producing staggering amounts of bioinformation, are bound to raise new issues that reanimate the philosophical and bioethical paradigms of the recent past. But what do these challenges amount to and what would be needed in order to address them in adequate ways?

The article will start with a short historical retrospect concerning the maturation of utopian ideas into scientific research practices as outlined above, focussing on literary writings by Wells, Huxley and (finally) Houellebecq. Building on this concise historical review of fiction and forecast, I will then address the question what kind of future is awaiting us, what kind of utopia (or dystopia) is implied in contemporary genomics science as it is currently emerging, and what this entails for the conceptual frameworks and methods of biophilosophers and bioethicists. In order to address this question, I will first of all reflect on recent writings of the German philosopher Peter Sloterdijk and, to a lesser extent, on 
those of Michel Foucault. Notably in his provocative lecture "Rules for the human park" (1999/2001), Sloterdijk deliberates precisely on this type of issue by announcing the emergence of what he refers to as a new wave of "anthropotechnologies", technologies that pervade our "essence" (notably our genome and our brain) and the question will be how we are to assess them in terms of "biopower" and "practices of the Self". Subsequently, in order to move from a panoramic and philosophical to a more concrete and bioethical level, I will focus on two particular fields of application where the implications of genomics for biomanagement are now beginning to present themselves and that therefore constitute important stage settings for exploring the future uses of genomics and bioinformation, namely the professional sports domain and the animal husbandry domain.

\section{The Beginning: The Year 1900}

The year 1900 has been regarded as a quantum leap in the history of science, a kind of Cambrian Explosion of novel ideas. In the realm of the humanities, Freud launched the psychoanalytical movement with his Interpretation of Dreams and Husserl launched the phenomenological movement with his Logical Investigations. The sense of rupture was even more acute in the scientific realm, with the introduction of the quantum concept by Planck (thereby launching quantum physics), the introduction of the mutation concept by De Vries, the discovery of blood types by Landsteiner and (of course) the rediscovery of the work of Mendel. All of a sudden, the basic conviction proliferated among scientists working in various fields (like an intellectual epidemic) that nature does make leaps (natura facit saltus) and that characteristics of entities depend on the presence or absence of discrete elements, be it elementary particles, antigens or genes. This conviction was at odds with the idea, dominant throughout the 19th Century, that nature progresses through accumulations of infinitesimal changes. Darwin for example was so thoroughly convinced of this that he explicitly stated on no less than seven occasions in The origin of species that nature does not make leaps (natura non facit saltus).

In that same period, around the year 1900, biologist Jacques Loeb (1899/1905) put forward the idea that biology should give way to biotechnology. Organisms can be manipulated by adding certain chemical substances to their environments. He discovered for instance that, by manipulating their external milieu, "artificial parthenogenesis" (non-sexual reproduction) could be induced in sea urchins and he concluded that, in principle, artificial reproduction in "mammals" (that is: humans) would be possible as well. In the textbook The science of life (1931/1938), written by H.G. Wells (the science fiction writer who also was a prominent biologist) in collaboration with his son and with Julian Huxley (brother of Aldous), Loeb's ideas were discussed in an anticipatory manner: "In mammals (again: this should be read as humans) the ovum is inaccessible to the experimenter, so that we do not know whether artificial parthenogenesis is possible. There is no reason to suppose that it is not..." (1931/1938, p. 509). From here, Loeb's seminal biotechnological ideas made their way to the first chapter of Aldous Huxley's novel, which contains clear references to Loeb's experimental work. Basically, Loeb claimed that nature (including the human body) should be regarded as raw material for future biotechnologists to work with. Biologists should become bio-engineers, focussed on improving rather than on understanding nature (Pauly 1987).

Huxley's novel basically seems to suggest that at a certain point, reproduction (biologically speaking our most important "assignment" in life) cannot be left to individuals (or rather, to couples). Sooner or later, the modern nation-state has to assume its responsibility, has to begin to govern this process in a more rationalistic, scientific, post-fatalistic and evidencebased manner, in order to assure the physical and mental well-being and quality of life of the general population and of future generations through topdown family planning. Thus, Huxley's novel is a literary exploration of what Foucault (1976) and his followers have analysed in terms of biopolitics and biopower. In Huxley's novel, the state is seen as an immense biological plant, a giant hatchery for producing high-quality human beings, a modern, scientific version of Plato's science-based "ideal" state. Therefore, his novel is a modern counterpart of Plato's Republic, where the same proposition is put forward. In order to significantly enhance the performance of the city-state, the guardians will have to seize control over reproduction, training and education. 
The foresight genre, of which Brave New World constituted one of the highlights, was not an exclusively Western phenomenon. A similar discourse emerged simultaneously in the Soviet Union. Here, as in the West, utopian/dystopian ideas were vigorously explored in stories and essays concerning the artificial production of a new type of human beings, happy and productive, adapted to technology-driven social environments. And here as well, the replacement of natural (sexual) reproduction by artificial reproduction and parthenogenesis in the context of hatcherylike facilities constituted a crucial ingredient (Groys and Hagemeister 2005).

As far as Western sources are concerned, there is a clear "genealogical" connection, via Loeb, from Wells to Huxley. Besides authoring science fiction novels, H.G. Wells also published biological treatises and essays. In 1902, he published an article in Nature entitled The discovery of the future in which "two types of mind" were distinguished. The first and dominant type, he argued, is retrospective in habit and committed to learning from the past. The second type, however, is oriented towards the future. Whereas the former ("legal") type is "submissive", believing that what has been acknowledged in the past should also guide us through the present, the second ("scientific") type is creative and masterful and oriented towards change. This type of mind sees contemporary society as a workshop, and the present as no more than material for the future. Given the fact that science and technology have come to play such an important role in contemporary society, Wells argued, much more can be learned from exploring the future (through anticipations and extrapolations) than from exploring the past. Yet, it is still the past that dominates our lives and thoughts. Whereas sophisticated methods have been developed for carefully analyzing past events (history, archaeology, palaeontology, etc.), the exploration of the future has so far been left to novelists. Due to science, we have been able to produce a fairly clear picture of what life must have been like in the Roman era, or even in swamps and jungle forests of the Mesozoic age, for instance, but for some reason we keep underestimating our possibilities for producing visions of the future with a similar degree of accuracy. Knowledge of the future is attainable, however, Wells argues - and well worth attaining.

The century that began with Planck's quantum concept, Mendel's rediscovered paper, Loeb's experiments and Wells' summons to produce more foresight research, ended more or less with Michel Houellebecq's novel Elementary particles (1998). In this novel, literary extrapolations of our genomics future are combined with critical reflections on previous utopian projects and revolutions, as well as on Huxley's dystopian novel. In Houellebecq's book, the 20th century, notably the 1960s and 1970s, are presented as a series of revolutions or mass experiments. In critical and cynical terms the author reflects on the philosophical, political, sexual, cultural, technical and psycho-pharmaceutical experiments of past decades. All these revolutions, the author argues, resulted in fiasco's. Take for instance the philosophical revolution as it notably emerged in contemporary French philosophy. As Houellebecq points out, it ended with Deleuze committing suicide, Lacan becoming senile and Foucault falling victim to the consequences of his sexual experiments. Along similar lines, the other revolutions are "discussed" and discarded. The sexual revolution, he argues, resulted in pointless, meaningless sex, acted out not only in novels and movies but also in real life, the life-world of individuals, disconnected from procreation, and wholly devoid of love and attachment. The psycho-pharmaceutical revolution resulted in selfdestructive and irresponsible behaviour, fake experiences and malaise-and so on, and so on. Now, however, a new revolution has announced itself, that will finally succeed in delivering what the other failed to deliver, namely human happiness-although this apparently optimistic message should no doubt be interpreted in an ironic vein as well.

The main character of the novel, a scientist, managed to produce the algorithm that will allow us to reconstruct and optimize our genome, the essence of what we are. Thus, a new type of human beings can finally be produced, in order to replace the existing (unhappy) type. More or less at the same moment, in 1999, the German philosopher Peter Sloterdijk published his essay Regeln für den Menschenpark ["Rules for the human park"], that later became embedded as a chapter in an important volume on Heidegger (Sloterdijk 1999/2001), in which similar ideas are fleshed out. In his lecture, Sloterdijk presents a provocative view on the history and possible future of humankind. Human beings, he argues, are to a considerable extent self-made. Building on seminal Nietzschean ideas, he presents human history as a 
narrative of self-domestication and self-amelioration. Until recently, Sloterdijk argues, humanistic strategies have been tremendously important in this respect, notably through the emergence of literacy: the ability to read, write and exchange letters and books, thus enhancing the pace of communication, life and history, while opening up avenues for communication and "epistolary friendship" even between individuals belonging to different historical periods. Reading and writing are seen by Sloterdijk as techniques or practices of the Self, to use the Foucauldian term, as "anthropotechnologies", allowing us to create new cultural environments and to adapt ourselves to our self-made socio-cultural world through education. Through practices such as literacy, we became what we essentially are, or believe ourselves to be, namely autonomous, rational and responsible individuals.

However, in the near future, Sloterdijk argues, these humanistic strategies may no longer suffice to intensify the process of self-edification. At a certain point, biotechnologies may be put to use as "anthropotechnologies" in order to open-up new possibilities in this direction - as was also suggested in Houellebecq's novel. But what exactly does Sloterdijk mean by that? In the next section, I want to analyse his ideas, that caused something of a scandal at their time of publication, in more detail.

\section{Anthropogenesis: The Coming into Being of Human Beings}

In order to explore the contours of a future "human park", Sloterdijk's lecture begins at the beginning, with an updated philosophical vision of our early prehistoric past. Building on ideas articulated by Nietzsche he argues that, unlike other domesticated animals, human beings more or less domesticated themselves, thus occupying both the subject and the object pole of the domestication process-we have been both our shepherd and our herd. According to Sloterdijk, philosophers until now have consistently failed to acknowledge and consider the pivotal role of self-domestication in the process of anthropogenesis (the coming into being of humankind).

Notably the Neolithic revolution (the introduction of agriculture) was crucially important. Since then, we became sedentary beings who created an artificial ecosystem, a socio-cultural sphere of our own, a kind of incubator or hatching facility where animals were domesticated, plants were cultivated, individuals were educated and stories were exchanged-transmitted from one generation to the next. Our philosophical blind spot, according to Sloterdijk, has always been the extent to which our own early history is intimately connected with the history of (other) species we actively domesticated. Our view of history has always been "humanistic" and therefore biased in the sense of being overtly anthropocentric.

This view, articulated by Sloterdijk in 1999, shortly before the theatrical unveiling of the human genome sequence, is confirmed by contemporary genomics research as it has evolved since then. Until recently, human history was basically seen as a single-species narrative. Genomics, however, allows us to reconstruct our history in ecocentric terms, as a history of artificial ecosystems, where humans and other species (domesticated animals, cultivated plants, microbes involved in fermentation and the like) cohabitate and co-evolve. The genomes of the rice plant, or the potato, or the domesticated cow constitute bioarchives in which we find our own history reflected. While dramatically changing our domesticated animals and cultivated plants, we have simultaneously changed ourselves, by transforming our environment and thereby altering the course of our socio-cultural trajectories. We have drastically changed the conditions of our own evolution, our own history. Humanity as we now know it, is the outcome, the "product" of a development that can be reconstructed in a much more detailed manner than ever before due to the bioarchives made available by sequencing the genomes of the species involved.

From this perspective it becomes clear that biotechnology, in a broad sense of the term, covering any technological application using living organisms, has played a pivotal role in human history during the past ten millennia or so. Biotechnology in a more contemporary and narrow sense, however, namely in the form of technologies that allow us to transform and modify the genomes of species more directly, through genetic engineering and similar techniques, is likely to play a no less pivotal role in determining our future. Besides allowing us to reconstruct important chapters of early human history in a much more detailed manner than ever before, genomics and genome-related biotechnologies may also provide us with new opportunities for continuing this history in new directions, through 
the use of a new generation of "anthropotechnologies" that may redefine what we are and what we may become. This development is bound to pose unprecedented challenges to philosophy, completely resetting biopolitical and bioethical agendas. According to Sloterdijk, the question is whether philosophy (still dominated by the humanistic convictions of the past) is ready for these challenges. Yet, in order to assess the present and explore the future, we must begin at the beginning. How did we become the type of human beings we currently are in the first place?

The process of anthropogenesis, Sloterdijk argues, is intimately connected with processes of domestication and self-domestication. The house (domus in Latin) must be regarded as a "biopolitical complex" (p. 322) that set the stage for the process of anthropogenesis to take place. Besides taming "other" animals, we also managed to tame ourselves, the animal "within". This involved training, but also other domestication techniques such as selection (through uneven prospects for reproduction). This "bottom-up" and time-consuming process-bottom-up in the sense that in took place in houses and villages rather than through political institutions-resulted in a particular type of human being. In "humanistic" accounts of how we came to be what we are, this virtually unexplored pre-history of self-domestication is often "repressed", ignored or eclipsed.

Another important chapter in the history of anthropogenesis was the emergence of literacy. Sloterdijk describes how in the context of the Roman Empire the art of writing opened-up practices of the Self that allowed individuals to distance themselves from the "mass media" of the day, notably amphitheatres, where spectators were entertained with spectacular and atrocious shows. The reading and writing of letters and books allowed "friends of the alphabet" to develop a much more humane, less boisterous counter-culture. And this literacy-based counter-culture of epistolary networks for exchange between like-minded friends involved Stoics like Seneca as it did Christians like Saint Paul.

According to Sloterdijk, it is obvious that literacy presupposes self-domestication. Only people who inhabit a house (be it a roman villa, a monastery or a bourgeois mansion) are able to (learn to) write and read. All the typical attributes of literacy, of reading and writing (a chair, a table, a library, etc.), as well as related activities (such as walking or having a conversation in a garden) presuppose the existence of a house that may contain letters and books. Even a church is basically a house built for the purpose of reading (one particular) book. And the same goes, of course, for schools. A school is a house that is basically constructed for the purpose of learning to read (and perhaps also to write) books-similar to the way in which universities are premises where individuals learn to read and write scholarly papers. Until recently, moreover, schools were erected for the purpose of learning to read particular types of book, notably books that were part of the national cultural canon, written in a more or less artificial national language that tended to differ from the various verbal dialects spoken at home or in the local village. Thus, literacy not only involved the introduction of new tools for self-enhancement (the acquisition of new communicative skills), but also a replacement and recontextualisation of the process of "producing" and shaping human beings, from homes and hamlets to novel types of buildings, directed towards discipline and control. This also resulted in new forms of selection. The individuals (pupils) involved in these school-type practices could well be regarded as objects and targets, rather than as subjects of the process.

According to Sloterdijk, however, we are now entering an era in which new possibilities for selection and self-enhancement present themselves, for instance in the form of pre-natal selection, in the context of IVF. Increasingly, and contrary to what was suggested in Huxley's novel Brave New World, this process is individual-driven, rather than state-driven, and will allow individuals to occupy the "subject" rather than the object pole of the process. They themselves are the ones that will be increasingly exposed to a proliferation of technology-based opportunities for reproductive choice. This is not by definition a pleasant situation, far from it. According to Sloterdijk, contemporary human beings clearly display a profound uneasiness towards these new possibilities for exerting biopower, and rightly so, for these possibilities seem much more powerful and consequential than the ones we have been able to sufficiently familiarised ourselves with in the past (p. 328). Yet, according to Sloterdijk, instead of deciding to refuse to use these new possibilities for biopower at all—which may well be our first impulse, but also a dead alley and a form of escapism -, we rather should 
face the challenge of formulating a new codex for the use of emerging anthropotechnologies (p. 329). Whether and to what extent these new anthropotechnologies will bring about a dramatic change of human phenotypes and genotypes, through a conscious shift from reproduction "fatalism" to genomics-based selection, may still be an open question as yet, but should nonetheless become a major issue of concern. As Kant already indicated, it is typical for human beings to be confronted with question they seem neither able to resolve nor to ignore, and the issues raised by newly emerging anthropologies clearly seem to fall under this heading.

At the same time, Sloterdijk reminds his readers of the fact that such issues are not completely without precedent. In a number of dialogues, notably Politikes, Plato already deliberates on issues involved in the management and amelioration of humankind. In Plato's view, the ancient polis emerges as a kind of human park, where enlightened aristocrats see it as their responsibility to govern human reproduction in a rational manner for the benefit of the state. Thus, the polis emerges as a kind of hatchery where human beings are produced-an ancient precursor of Huxley's Brave New World. According to Sloterdijk, the question is not whether we will decide to use emerging anthropotechnologies such as prenatal selection or gene therapy in the future-there can be no doubt that we will-but rather how we are to organize their use in such a way that human individuals may become the "subjects" rather than the "objects" of the process, the authors rather than the targets of these emerging bioexperiments.

A similar perspective has been voiced by Michel Foucault in 1976, when the notion of biopower was introduced by him, and once again in 1984 with the introduction of the notion of the "care for the Self". In 1976, he explored how, in the 19th century, nation states began to take an interest in (or rather, to develop serious concerns regarding) the physical well-being of their populations, notably of the lower social strata. These concerns were driven by the consideration that the physical well-being of the masses (in terms of health care, food, housing, hygiene, etc.) constituted a major factor of economic and military importance. Various biopolicies were designed for the purpose of monitoring and improving the physical condition of large numbers of people. Thus emerged the concept of public health. From this perspective, individuals were the objects or targets, rather the authors or initiators, of biopolitics. In 1984, however, a different perspective was opened-up. Now, Foucault became interested in the practices individuals themselves may engage in to shape and manage their own life and care for their own body and health. Like Sloterijk, Foucault indicates that this should not be seen in terms of an Either/Or: to domesticate or to be domesticated. This was rather the way in which the issue was framed by Plato, building on a dichotomy, a basic distinction between two types of human beings, namely aristocrats and slaves, those who can and those who cannot reasonably be granted the responsibility to care for themselves as well as for others. According to Plato, this dichotomy represented a "natural" distinction, almost amounting to a demarcation between two different subspecies. In the view of authors such as Nietzsche, Foucault and Sloterdijk, however, things are much more complicated. Domestication of others and of ourselves are processes that are complementary and closely connected. In various situations individuals may occupy various positions. Both biopolitics and care for the Self, both domestication and Self-domestication constitute pivotal dimensions or axes of the pastoral complex. We cannot "decide" whether to domesticate or be domesticated, to be disciplined or to manage our own life, as we are always involved in both processes. Rather, the question is how to assume the subject-position as consciously as possible. In the face of newly emerging biotechnologies, how can we really position ourselves in such as way that we will be able to influence and govern our own future, both as individuals and as societies? According to Sloterdijk, the humanistic response, a discourse that basically rejects the newly emerging anthropotechnologies as being at odds with and as constituting a threat to human "dignity", can no longer be expected to provide us with viable answers. The "post-human" response rather argues that our "dignity" resides in the fact that we can be, and often have been, in a position that allows us to form and reform ourselves, with the help of a broad range of techniques, from reading and writing letters and diaries up to prenatal diagnostics. Our "essence" resides in our ability to shape, manage and transform ourselves. We have never been satisfied with ourselves, we have always kept working on ourselves, always interested in 
developing new tools for self-amelioration, and there is no reason to suppose that we will stop doing so in the future.

\section{Anthropotechnologies: Ancient and Emerging}

Ten years after the publication of his human park essay, Sloterdijk (2009) published an important sequel in which the history of anthropotechnologies is fleshed out from an individual (or ethical) rather than from a political perspective. The history of humankind is seen as a history of emerging practices of selfimprovement. Since time immemorial, human beings have been pushing performance boundaries through spiritual, mental and physical exercises. An important chapter in this history is the Renaissance of the professional athlete and the resurge of the ancient stadium (the modern arena) around 1900. The inauguration of the first Olympic Games (Athens 1896, Paris 1900, etc.) exemplified the breakthrough of the neo-Olympic movement, the neo-athletic syndrome. Since then, top sport has emerged as a practice of continuous self-improvement and enhancement through anthropotechnologies (training schedules, diets, special techniques, dexterity of movement, respiratory regimes, high-altitude training, etc.). Again, Sloterdijk develops his diagnosis of the present through a series of flash-backs to important beginnings. And once again, a major point of departure, also for the history of anthropotechnologies, is Plato's Academy, a training site devoted to athletics and philosophy, to physical and mental gymnastics, as well as to trainer-athlete interaction.

Building on Sloterdijk's diagnosis I would argue that the basic objective of Plato's anthropotechnologies or practices of the Self is already fleshed out in his famous simile of the cave, a staging that in many respects seems to have served as model or archetype for Huxley's opening passage cited above:

Picture men dwelling in a sort of subterranean cavern... Conceive them as having their legs and necks fettered from childhood, so that they remain in the same sport, able to look forward only, and prevented by the fetters from turning their heads... etc. (Plato 1935/2000, 514).

At a certain point, some of these hyper-domesticated human beings are freed from their chains. They are literally "educated", that is: they begin to move upwards, towards the light. This, however, is a painful and time-consuming process, involving training and exercise, for instance training of the sense organs. Moreover, once the individuals involved are sufficiently enlightened, they will find it impossible to return to their former positions. Plato's uncanny and at first instance rather bizarre scene reads like a Paleolithic hatching facility for producing human beings, a Flintstone-like version of Huxley's biotechnological assembly line. These prisoners may also be seen as human cattle, subject to practices of human "husbandry". Their very position is similar to that of domesticated animals in contemporary bio-industry. As such, the simile seems to indicate that, as a purely biological entity, human beings are still far from finished, far from human. Therefore, they are to be subjected to anthropotechnologies in the form of training schedules and educational modules. Only a select number of them will become intellectual top athletes bound to greatly surpass untrained (fettered) human beings in terms of physical or intellectual performance. In Plato's days, this miracle of selfimprovement and self-enhancement was performed through training (paideia) alone. Perhaps that now, new types of anthropotechnologies may allow us to push our physical and mental boundaries even further?

\section{Bioinformation and Enhancement}

Philosophers, novelists and other masters of the imagination have used their art to explore their way into our present and future. Genomics, notably the sequencing of the human genome, initially on a general ("species") level, and now increasingly in an individual level as well (allowing future citizens to consider the strengths and weaknesses of their own genetic constitution through personalised genomics information), in combination with proliferating biotechnologies, allow us in principle to use this information in order to (continue to) enhance ourselves. The question how we are to use this new type of biopower can no longer be ignored. Are we about to make another significant leap in the history of self-formation?

It seems predictable that genomics-based bioinformation will increasingly affect the ways in which we (as individuals and as societies) will manage our individual and public health. Initially, the focus will 
be on the use of bioinformation as information, notably for purposes of prevention, through adapting our life-style (food, environment, therapy, career choice, etc.) to the information provided by sequencing genomes. This will also involve various forms of training: we will have to learn to interpret this type of data into meaningful options and choices. The next step, somewhat more futuristic perhaps, but nonetheless already explored in various contexts such as animal laboratories not wholly unlike Plato's cave in terms of spatial organisation, will consist of developing technologies that will allow us to actively influence our organism, our genome, on the basis of genomics information. For instance, modified viral genomes may be introduced in human bodies in order to produce certain tissues or certain neurotransmitters in a tailored and targeted manner to counteract the effects of ageing or degenerative disorders. Those who distance themselves from such scenarios under the pretence that they seem fictitious and unrealistic, are apparently ignorant of the extent to which such research trajectories are already designed and conducted in laboratories worldwide exactly for this purpose, using animal models. Bioethics and biopolitics cannot afford to put themselves consciously behind schedule by closing their eyes for these developments. Rather, we should train ourselves in a new style of ethical thinking, designed in close proximity and interaction with experts involved in these technoscientific developments, in order to address the opportunities and dilemma's they entail.

In contrast to what Huxley suggested in his novel, I do not find it all that plausible that future generations will begin their life in a test-tube as mass-produced individuals in a centralised hatching facility. What is much more likely, however, and no more than an extrapolation of already existing and established research practices, is that somewhere in the near future, say 2020 or so, at the beginning of their life, individuals will be taken by their parents to a genomics facility where, in the form of a heel-prick test, their personal genome will be sequenced. The sequence thus acquired can be used for public health research, but will also be available and downloadable for the individuals involved, stored in the form of giant databases, or by their physicians at their request, for whatever purpose (dietary reasons, health problems, career choice, buying a house, reproductive choices, and so on). There will be avant-gardes of course, pioneer groups such as patient suffering from life-threatening diseases, risk groups, special professions or top athletes, who will resort to such practices somewhat earlier than others. Top athletes for instance will be interested in adapting their training schedules and food intake, or even their use of doping products, to the idiosyncracies of their personal genome. For various reasons, the use of genomics bioinformation by athletes constitutes a kind of experimental setting, a laboratory that provides a preview of practices that are bound to spread (as a kind of technological epidemic) to other contexts as well, at a somewhat later stage. Therefore, sport genomics offers a fascinating case study for exploring the imminent future of public health. In the two final sections I intend to further explore these issues with the help of top athletics as a special file that builds on two "beginnings" already outlined above, namely Plato's simile of the cave (symbolising what has been called the emergence of human thinking and of classical intellectual and athletic ideals around 500 B.C.) and the emergence of neoathleticism around 1900.

\section{Top Athletes as Pioneers of the Genomics Era}

The combination of genomics with high level sport activities has already aroused much attention and debate. One of the scenarios is that in the near future "normal" sport professionals will increasingly have to compete with "genetically modified super-athletes" and that the Olympics of the future will increasingly be dominated by the latter (Miah 2004). A second scenario emphasises the role of "gene doping", i.e. the non-therapeutic use of cells, genes, genetic elements, or the modulation of gene expression, having the capacity to improve athletic performance (idem). A third scenario rather focuses on the use of genomics information in the context of training. In this scenario, the future Olympics will be dominated by genetically "normal" (that is, unmodified) athletes working in close collaboration with (teams of) experts and trainers who know how to make use of new types of genomics information in the context of diets, training programs and nutritional supplements ('nutriceuticals'). Thus, existing anthropotechnologies will not become outdated and replaced, but rather amplified and complemented by 
genomics information. And of course, a combination of scenario's is also possible, where "gene doping" regimes are tailored to individualised genomics information and vice versa.

So far, a substantial part of the discussion on genomics and top sport has either focussed on genetic manipulation and gene doping, or on the use of genomics information in the context of prevention (Jordan 1998). In the first case, the debate addresses issues involved in the production of "super" athletes through conscious manipulation of human genomes and human bodies. Technologically speaking, possibilities in this direction will remain quite limited for the years to come, so that there is a substantial element of science fiction and utopia (or dystopia) in these debates: they constitute reflections on thought experiments rather than on on-going developments. As Sloterdijk (2009) phrases it, genetic manipulation may remain a mere anecdote in the annals of athleticism. Nonetheless, research with animals shows that genomes can be transformed dramatically and that physical characteristics of mammals (such as bodily weight and muscular strength) are certainly open to manipulation. The question remains, however, to what extent these laboratory findings can and will be extrapolated to human subjects, given both the biological and the ethical restrictions in this area. So far at least, transgenic animals did not, as the statues of ancient Greek sculpture once did, arouse potential athletes to mimic and follow their examples.

When it comes to prevention strategies, genomics information, notably the presence of particular genes associated with increased risk for health problems such as heart disease or Alzheimer, could be used to preclude carriers of "risk genes" from entering particular sports, notably on a high performance professional level, such as professional soccer or boxing. Although these debates are interesting in themselves, a perhaps even more relevant impact of genomics on elite sport (proliferating from there to other practices) will evolve in a somewhat different direction in the sense that genomics information will be increasingly used to improve training and food regimes by tailoring parameters such as diet and climate (optimal training latitude and altitude) to personalised genomics information.

Increasingly it will become possible for genomics information to become "personalised". Although it may take some years to complete an affordable personal whole-genome sequence (the famous $\$ 1.000$ genome), SNP-arrays allowing the detection of relevant polymorphisms and variation throughout the whole genome are becoming increasingly affordable for individuals, and this will notably apply to top athletes. The top athlete and his or her trainer constitute a team that is on the look-out for novel forms of information. Continuous innovation in terms of technique, training programmes and dexterity improvement makes and accounts for the (often slight) differences. There is no doubt that the further development of this scenario has the potential of revolutionizing professional sport as we now know it. By providing top athletes and their trainers and physicians with individualised genomics information, it will become increasingly possible for them to adapt life-style, nutritional diet and training programmes, but also doping intake, to the strengths and weaknesses indicated by the personalized genomics profile. Interventions may become more targeted and tailor made. Gradually the focus will shift moreover from damage repair to prevention of harm and, on the conceptual level, from focussing on the presence or absence of single genes associated with particular characteristics (a monogenetic approach), to wholegenome association studies (a genuinely genomics approach). Rather than promoting one ideal diet or training method for all athletes, highly individualised schedules will be developed on the basis of personalised genomics information.

\section{Top Athletes as "Laboratory Animals" or "Athlete Husbandry"}

The basic morale of Plato's simile of the cave can be formulated as follows: due to training and education as anthropotechnologies, human beings find themselves midway on a journey between two poles, namely on the one hand the pole of the self-domesticated, selfsubjugated animal leading a slave-like existence, and on the other hand the pole of the top athlete (be it in an intellectual, physical or artistic sense) leading a life of asceticism, exercise and top level performance. This may also be reframed in a somewhat different manner: we human beings constitute the mean between two extremes, or rather two types of animals that mirror or exemplify the two human poles outlined above, namely the domesticated animal on the one hand and 
the laboratory animal on the other. The latter is a kind of outpost into our own future, a highly transparent body whose physiological and genomic make-up is documented and controlled in an extremely detailed and precise way. Ter Gast (2007) has indicated how laboratory mice, inhabiting the research facilities of the present in astounding numbers, leading their cavelike existence in high-tech environments, may actually be regarded as "biotech pioneers" exploring and already entering our own human future. Not only because they are inflicted with the disorders from which we ourselves are bound to suffer somewhere in the future, and subsequently subjected to the treatments that we ourselves will be subjected to once those treatments are regarded as safe enough (and we ourselves are regarded as ill enough) to do so. An animal laboratory is like a theatre where possible personal futures are acted out. Not only in terms of therapy and disease, but also in terms of enhancement. To put it bluntly: what works in mice, may sooner or later be offered to humans. Whoever visits an animal research facility may well cite what the American journalist Joseph Lincoln Steffens phrased after his visit to the Soviet Union in the heydays of technoscientific utopia referred to above: "I have seen the future and it works" (Kaplan 1974). What we are currently doing to mice in terms of size, muscular strength and longevity may well mirror some of the practices that will emerge in human health policies of the future. Not in the sense that we ourselves will come to inhabit assembly line, Brave New World facilities, but in the sense that particular elements of these research trajectories may well become embedded in biomedical therapy, prevention and enhancement trajectories of the future. We cannot discard such a development simply by saying that it would be at odds with human dignity, as this would ignore the usual migration routes of knowledge claims and their biomedical applications from animal laboratories into hospitals and training sites or top sport facilities for humans.

But when it comes to exploring our own future, we may as well start from the other side of the spectrum, namely animal husbandry genomics or livestock genomics. ${ }^{1}$ Here, genomic sequencing information is used to tailor food and housing regimes to the genomes of the livestock involved in order to achieve

\footnotetext{
${ }^{1}$ http://lgu.umd.edu/lgu_v2/homepages/home.cfm?trackID= 2715
}

an optimal fit between genome and environment as well as for identification, monitoring and surveillance of farm animals or herds. Animal corporeality is "translated" into bioinformation (Harvey 2007). This information may be used to enhance selection and reproduction policies. This may further the production of top performers and "farmyard supermodels" (Harvey 2007, p. 15), but genome information may also be used to reduce phosphate excretion by tailoring food regimes to genomic profiles. As is indicated in Plato's simile, the difference between human and non-human domesticated animals is that, whereas the fettered animals are merely the passive objects and targets of such technologies, human beings (released from their chains) may decide to use this type of information for performance enhancement on their own accord, although, as Plato explains, an element of coercion is bound to be present in the early stages of this process. In this manner, genome illiteracy gives way to the embedding of bioinformation in training and life-style regimes of top performers such as professional athletes. Thus, in the human context, in the context of top level sport it is imaginable that individuals themselves, in collaboration with coaches and health experts, will increasingly use personalised genomics information in order to develop optimal diets, career choices and other life-style decisions. Or, to use another example, the 21st century will not be a Brave New World where 'super employees' will be artificially produced by means of genetic modification. What is much more likely is that in the near future, various possibilities for pre-employment genetic screening (PEGS) will affect the course of professional careers in the sense that individuals themselves will tailor their diets and career decisions, as well as the design of their working environment, to personalised information concerning their relative strengths and weaknesses as reflected by their genomes (Holzman 2003).

Thus, top athletes may be regarded as a kind of avant-garde, as pioneers leading the way into the future of public health genomics, where more and more opportunities for using personalised genomics information, as well as for translating this information into concrete life-style options for individuals, may present themselves. Thus, reflections on the ways in which the availability of genome information affects top sport is not only of interest for the athletes 
involved, but also for society at large, as certain uses of genomics information may spread from limited groups (top athletes, patients, risk groups, special professions) to the broader society of "ordinary" citizens (the research subject of an epidemiology of technology).

In 2007, Nature Genetics published a question of the year on its website, allowing experts from various backgrounds to explicitly consider possibilities for using personalised genomics information in the future. The discourse thus emerging could be regarded as an "ethical" laboratory, where future issues are explored by well-informed individuals in an interactive manner, responding to one another. Besides (and in combination with) academic desk analysis, the normal trade of philosophers and ethicists, and besides (and in combination with) literary explorations of genomics futures by professional novelists and science writers, such podiums provide an interesting source of complementary input for our effort to map the societal future of genomics.

On June 26 2000, Clinton, Collins and Venter presented the human genome sequence as a kind of map. Like the Lewis \& Clark map, to which the human genome map was explicitly compared, it was a physical map, indicated rivers, mountains and various other physical elements as exactly as possible, providing the necessary input for a rather consequential emerging practice: the colonisation of the American West. Today, the challenge will be to present a social-geographical map, indicating in various domains and regions how human genomics information is used, or bound to be used, and what infrastructures are emerging that may allow us to govern this process in such a manner that individuals may position themselves as the subjects, rather than as the objects, as the performers rather than the targets, of this consequential development.

Open Access This article is distributed under the terms of the Creative Commons Attribution Noncommercial License which permits any noncommercial use, distribution, and reproduction in any medium, provided the original author(s) and source are credited.

\section{References}

Engels, F. 1880. Die Entwicklung des Sozialismus von der Utopie zur Wissenschaft. In Band 19 (1875-11883), ed. K. Marx and F. Engels Werke. Berlin: Dietz Verlag.

Foucault, M. 1976. Histoire de la sexualité 1: La volonté du savoir. Paris: Gallimard.

Foucault, Michel. 1984. Histoire de la sexualité 3: Le souci de soi. Paris: Gallimard.

Groys, B., and M. Hagemeister (Hrsg.) 2005. Die neue Menschheit. Biopolitische Utopien in Russland zu Beginn des 20. Jahrhunderts. Frankfurt: Suhrkamp.

Harvey, M. 2007. Animal genomics in science, social science and culture. Genomics, Society \& Policy 3 (2): 1-28.

Holzman, N. 2003. Ethical aspects of genetic testing in the workplace. Community Genetics 6: 136-138.

Houellebecq, M. 1998. Les particules élémentaires. Paris: Flammarion.

Huxley, A. 1932/1947. Brave new world. London: The Albatros.

Jordan, B. 1998. Genetic susceptibility to brain injury in sports: A role for genetic testing in athletes. The physician and Sportsmedicine 26 (2): 25-26.

Kaplan, J. 1974. Lincoln Steffens: A biography. New York: Simon \& Schuster.

Loeb, J. 1899/1905. On the nature of the process of fertilization and the artificial production of normal larvae (plutei) from unfertilized eggs of the sea urchin. American Journal of Physiology, 3, 1899, 135-138; Reprinted in: Loeb, Jacques (1905) Studies in General Physiology (Vol. 2), 539543. Chicago: University of Chicago Press.

Miah, A. 2004. Genetically modified athletes. Biomedical ethics, gene doping and sport. London \& New York: Routledge.

Pauly, Ph.J. 1987. Controlling life: Jacques Loeb and the engineering ideal in biology. New York/Oxford: Oxford University Press.

Plato. 1935/2000. The Republic VI-X. (trans: Shorey, P. Loeb Classical Library. Plato VI). Cambridge: Harvard University Press.

Sloterdijk, P. 1999/2001. "Regeln für den Menschenpark". In Nicht gerettet. Versuche nach Heidegger. Frankfurt: Suhrkamp, 302-337.

Sloterdijk, P. 2009. Du musst dein Leben ändern. Über Anthropotechnik. Frankfurt: Suhrkamp.

ter Gast, E. 2007. Biotech engineers. A philosophical inquiry concerning the genetically engineered mouse. Thesis. Nijmegen: Radboud University Nijmegen.

Wells, H.G. 1902. The discovery of the future. Nature 65: 326331.

Wells, H.G., J. Huxley, and G.P. Wells. 1931/1938. The Science of Life. London: Cassell. 